\title{
Complicated Weil Disease
}

\author{
Vitorino Modesto dos Santos
}

Department of Internal Medicine, Armed Forces Hospital and Catholic University of Brasília, Brasília-DF, Brazil

To the Editor,

I read the very interesting letter by Ebik et al. (1) about the efficacy of prednisolone to control thrombocytopenia in a patient with severe manifestations of leptospirosis or Weil disease. This cosmopolitan disease is due to pathogenic agents of Leptospira interrogans species $(2,3)$. The patient presented with the classical features of "Weil's syndrome" - fever, jaundice, renal failure, and bleeding (2,3), and underwent adequate hydration and antibiotic therapy (1). Despite the appropriate management, the very low platelet levels persisted; therefore, the authors successfully utilized prednisolone $(1 \mathrm{mg} / \mathrm{kg})$ to control the thrombocytopenia (1). They focused the main current hypotheses related to the physiopathology mechanisms of thrombocytopenia in patients with renal failure due to severe forms of leptospirosis (1). Moreover, the favorable role of the early administration of corticosteroid was emphasized (1).

In this setting, I would like to add comments about the occurrence of accentuated thrombocytopenia in icteric as well as anicteric severe leptospirosis in Brazilian patients $(2,3)$. In particular, the very low platelet counts were similar either in the presence or absence of renal failure and Weil's syndrome $-61 \times 10^{3} / \mathrm{mm}^{3}$ and $82 \times 10^{3} / \mathrm{mm}^{3}$, respectively $(2,3)$. Septicemia during the early phase of disease might explain the thrombocytopenia in both patients, who showed a good improvement following clinical support and antibiotic administration; because of the rapid normalization in platelet counts, corticosteroids were not utilized $(2,3)$. The authors highlighted the major concerns involving thrombocytopenia in leptospirosis the possibility of diagnostic pitfalls with dengue fever, yellow fever, Hantavirus infections, or malaria occurring in the same environments, or coinfections with those mentioned conditions (2-4).

Travel to developing areas can enhance the occurrence of imported infections to industrialized countries. The current growing number of Zika virus infections, which can also be associated with thrombocytopenia, has increased the range of misdiagnosis or co-infections, mainly because false-positive tests with dengue fever have been recently described (5). In order to rule out eventual co-infections, routine serological tests including the most prevalent agents should be performed upon the admission of patients from respective endemic areas. The author believes that the commented articles would contribute to a better understanding of challenging items related to the diagnosis and control of these infectious causes of low platelets. Finally, one should also consider the need for further studies involving a greater number of cases to better evaluate the suggested advantage of early corticoid therapy in these conditions.

\section{Ethics Committee Approval: N/A.}

\section{Informed Consent: N/A.}

Peer-review: Externally peer-reviewed.

Conflict of Interest: No conflict of interest was declared by the authors.

Financial Disclosure: The authors declared that this study has received no financial support

\section{REFERENCES}

1. Ebik B, Tanriverdi Z, Öygen Ş, Kayran Y. High efficacy of prednisolone in a complicated case of Weil disease. Balkan Med J 2016;33:119-20. [Crossref]

2. dos Santos VM, dos Santos JA, Sugai TA, dos Santos LA. Weil's syndrome. Rev Cubana Med Trop 2003;55:44-6.

3. Santos VM, Santos UM, Gebrin DG, Santos AM, Cancado AC. Anicteric leptospirosis with pneumonitis, pericarditis and acalculous cholecystitis. Infez Med 2014;22:236-40.

Address for Correspondence: Dr. Vitorino Modesto dos Santos, Department of Internal Medicine, Armed Forces Hospital and Catholic University of Brasília, Brasília-DF, Brazil Phone: +55 61999668613 e-mail: vitorinomodesto@gmail.com

Received: 21 February 2016 Accepted: 20 April 2016 • DOI: 10.5152/balkanmedj.2016.16300

Available at www.balkanmedicaljournal.org

Cite this article as:

dos Santos VM. Complicated weil disease. Balkan Med J 2016;33:480-1 
4. dos Santos VM, de Sá DA, Martins RR, Paz BC, de Oliveira ER, Barcelos Mdos S. Hantavirus pulmonary syndrome coexistent with dengue. Indian J Chest Dis Allied Sci 2010;52:24951.

5. Gyurech D, Schilling J, Schmidt-Chanasit J, Cassinotti P, Kaeppeli F, Dobec M. False positive dengue NS1 antigen test in a traveller with an acute Zika virus infection imported into Switzerland. Swiss Med Wkly 2016;146:w14296.

\section{AUTHORS' REPLY}

Berat Ebik $^{1}$, Zülkif Tanrıverdi² ${ }^{2}$ Şuayp Öygen ${ }^{3}$, Yusuf Kayran ${ }^{4}$

${ }^{1}$ Department of Internal Medicine, Ergani State Hospital, Diyarbakır, Turkey ${ }^{2}$ Department of Cardiology, Balıklıgöl State Hospital, Şanlıurfa, Turkey ${ }^{3}$ Department of Rheumatology, Akdeniz University School of Medicine, Antalya, Turkey

${ }^{4}$ Department of Neurology, Special Tatvan Can Hospital, Bitlis, Turkey

We kindly thank Santos VM. for his sincere interest in our article (1). The authors report thrombocytopenia in leptospirosis might be stemmed from other factors apart from the disease, and thus, they emphasize these factors and the effects of early corticosteroid treatment shall be studied.

In our case, elevated liver enzymes, icterus and thrombocytopenia were present at the time of appliance. Therefore, by considering viral hepatitis and other specific viruses affecting liver, only a supportive care was launched. From the tests analyzed, Hepatitis A, -B, -C, toxoplasma and cytomegalovirus were found negative. As Dengue Fever and Hanta virus infections are not endemic pathogens in the area where we live, no specific test was done to evaluate these agents. Moreover, that crimean-congo haemorrhagic fever caused by Nairo viruses and infected by ticks was commonly diagnosed in the area was also taken into consideration. However, from the detailed anamnesis of the patient with a long lasting fever, we found that he had worked in a wooden fruit crate production facility and there were so many mice in the working environment, thus, we concluded that it was highly possible that the patient might have contacted with mice urine and scat. Depending on these findings and by primarily considering the patient had a leptospirosis infection, we drew blood for microscopic agglutination and it was positive.

About the patient with thrombocytopenia during appliance, the findings were related to septicemia, hence, a corticosteroid treatment wasn't decided because during the course of viral infections and septicemias, that corticosteroid into the treatment might cause problems is known (2). In clinical follow-ups, we first applied random thrombocyte to the patient with deepen- ing thrombocytopenia and developed epistaxis in order to provide bleeding control. However, since we didn't have enough thrombocyte increase and weren't able to control bleeding, we thought the patient could be suffering from pulmonary hemorrhage caused by severe leptospirosis, and we started corticosteroid treatment (3). In literature, we discovered thrombocytopenia caused by severe leptospirosis is a common condition and the condition might cause pulmonary hemorrhages and plasmapheresis and corticosteroid treatments are helpful for these patients $(4,5)$. Since we could not perform plasmapheresis, we gave corticosteroid and monitored the patient closely. Then, the level of thrombocytes increased whereas epistaxis decreased. After bleeding control was achieved, corticosteroid session was ended by giving lower doses.

From the case, reaching the conclusion of "corticoteroid treatment is required in the early phase of the case of thrombocytopenia in severe leptospirosis" is incorrect. However, for the patient with deepening thrombocytopenia and that was unable to have clinical improvement even after random thrombocyte suspension, we managed to apply corticosteroid treatment successfully and we also think that in the management of the case where other pathogens were inhibited, early corticosteroid treatment undoubtedly helped. For a better understanding of its positive effects in similar cases, more studies with a significant number of patients are required.

\footnotetext{
Address for Correspondence: Zülkif Tanrıverdi, Department of Cardiology, Balıklıgöl State Hospital, Şanlıurfa, Turkey

Phone: +905068823335 e-mail: ztverdi@gmail.com
}

\section{REFERENCES}

1. Ebik B, Tanriverdi Z, Öygen Ş, Kayran Y. High Efficacy of Prednisolone in a Complicated Case of Weil Disease. Balkan Med J 2016;33:119-20. [Crossref]

2. Minneci PC, Deans KJ, Eichacker PQ, Natanson C. The effects of steroids during sepsis depend on dose and severity of illness: an updated meta-analysis. Clin Microbiol Infect 2009;15:30818. [Crossref]

3. Schulze MH, Raschel H, Langen HJ, Stich A, Tappe D. Severe Leptospira interrogans serovar Icterohaemorrhagiae infection with hepato-renal-pulmonary involvement treated with corticosteroids. Clin Case Rep 2014;2:191-6. [Crossref]

4. Alian S, Asghari H, Najafi N, Davoudi A, Yazdani J. Corticosteroid in the treatment of moderate to severe thrombocytopenia due to leptospirosis. Iran Red Crescent Med J 2014;16:e16030. [Crossref]

5. Jayakrishnan B, Ben Abid F, Balkhair A, Alkaabi JK, Al-Rawas OA, George J, et al. Severe Pulmonary Involvement in Leptospirosis: Alternate antibiotics and systemic steroids. Sultan $Q a-$ boos Univ Med J 2013;13:318-22. [Crossref] 